\title{
A Gestão Participativa nas Escolas Públicas Municipais de Salvador e o nível de envolvimento da comunidade escolar
}

\begin{abstract}
RESUMO: Este artigo apresenta o resultado de uma pesquisa realizada em 2006, envolvendo a temática participação. Aborda os acessos e as dificuldades na participação da comunidade escolar (pais, alunos, professores, funcionários e gestores) na gestão das escolas públicas municipais em Salvador. $\mathrm{Na}$ formulação do problema foi definida a seguinte questão: quais os acessos e dificuldades de participação da comunidade na gestão de/das escolas públicas municipais de Salvador? Os principais objetivos da pesquisa foram: aprofundar os conhecimentos acerca da participação da comunidade no contexto organizacional e avaliar a amplitude da participação da comunidade escolar na gestão da escola através da elaboração, acompanhamento e avaliação do Plano de Desenvolvimento da Escola (PDE) nas escolas municipais de Salvador. A metodologia utilizada foi o estudo de caso. O resultado da investigação apresentou formas objetivas e subjetivas que facilitam e dificultam a participação efetiva da comunidade escolar por meio do Conselho Escolar (CE) numa gestão de perspectiva emancipável. E aponta uma concentração do poder decisório nas mãos dos segmentos gestores e professores. Esse último em menor grau.
\end{abstract}

PALAVRAS-CHAVE: Gestão democrática na escola. Participação democrática.

\section{Introdução}

A participação da comunidade escolar na gestão escolar é o resultado de uma luta não só dos profissionais da educação, mas, também, de toda a sociedade. Respaldada na Constituição Federal e em outras leis, a exemplo da Lei de Diretrizes e Bases da Educação Nacional (LDB), a participação da comunidade na gestão escolar pode tornar a escola mais democrática em suas decisões, apesar de não ser uma tarefa fácil. Sabe-se que em uma gestão organizacional existem diversas dimensões e variadas formas de participação, e é sabido ainda que a participação pode ser implantada tanto para atender objetivos libertários e de igualdade, quanto para aprisionar e manter uma situação de controle. Mas a gestão, ao abrir-se para a participação da comunidade nos assuntos da escola, por exemplo, estará educando para formar cidadãos, pois a participação constitui-se na "viga-mestra na construção da cidadania". (PINTO, 1995, p. 175)

O objeto de estudo é analisar a participação da comunidade representada no Conselho Escolar (CE), na gestão das escolas públicas municipais em Salvador, capital do Estado da Bahia, quan-
José Santos de Jesus Secretaria de Educação Municipal de Salvador jesusmail@ig.com.br

Jair Nascimento Santos Universidade Salvador jairsantos@unifacs.br 
(1) Notícia divulgada pelo MEC, em 14 de julho de 2004, disponível no seguinte endereco: http:// www.fundescola.mec.gov.br/ acessado em 17 jul. 2004. to ao seu acesso e suas dificuldades. Utilizaremos como referência de participação o nível de aproximação da comunidade escolar na elaboração, acompanhamento e avaliação do Plano de Desenvolvimento da Escola (PDE). Este plano constitui-se num instrumento de planejamento estratégico utilizado para melhor sistematizar e operacionalizar as rotinas implementadas no ambiente escolar, norteando a gestão da escola. Sua elaboração deve contar com a participação da comunidade escolar. (AMARAL SOBRINHO; XAVIER, 1999)

Respaldada na legislação (Constituição Federal e Estadual, Lei Orgânica do Município, Lei de Diretrizes e Bases Nacional da Educação (LDB), decretos, portarias e resoluções) concernentes à participação da comunidade escolar, a Secretaria Municipal de Educação e Cultura (SMEC) da cidade de Salvador vem tentando tornar as escolas municipais mais democráticas, incentivando o acesso da comunidade escolar no processo decisório da administração das escolas através, fundamentalmente, dos Conselhos. O artigo 34 da Lei Complementar 036/2004, publicada no Diário Oficial do Município, que dispõe sobre o estatuto dos servidores do magistério público do município do Salvador, define a comunidade escolar como um conjunto de indivíduos pertencentes às seguintes categorias: professores e coordenadores pedagógicos; funcionários; pais e alunos.

Nesse ambiente, a comunidade escolar, através dos seus representantes no Conselho Escolar (CE), deveria elaborar, implementar e avaliar o Plano de Desenvolvimento da Escola (PDE), pois, sendo ele um planejamento estratégico norteador da gestão escolar e a orientação constitucional da gestão escolar ser democrática, é natural, teoricamente, que haja uma participação democrática da comunidade. Entretanto, convém lembrar que o PDE tem a sua origem conceptual no Banco Mundial (BM), que, ao emprestar recursos financeiros destinados à área educacional no Brasil, impõe o cumprimento de determinadas normas inflexíveis e padronizadas quando da elaboração do PDE, produzindo, com isso, uma determinada dimensão no caráter participativo da comunidade ${ }^{1}$.

Examinado, embora brevemente, o Plano de Desenvolvimento da Escola (PDE), sua criação e o seu financiamento, ele é apontando por Amaral Sobrinho e Xavier (1999), como principal meio de participação da comunidade escolar na gestão da escola e como 
um instrumento que deve ser construído de forma coletiva e autônoma, constituindo-se numa das formas de incentivo à participação da comunidade escolar na gestão da escola.

O que se quer neste artigo é propor uma reflexão na busca do entendimento da participação da comunidade nas organizações escolares, cujo problema é saber: Quais os acessos e dificuldades da participação da comunidade na gestão das escolas públicas municipais de Salvador?

Diante desse problema, colocamos as seguintes questões de pesquisa:

a) Quais os mecanismos de acesso e participação da comunidade escolar na gestão das escolas municipais de Salvador?

b) Quais as dificuldades de participação da comunidade escolar na gestão das escolas municipais de Salvador?

Face ao exposto, buscou-se uma reflexão acerca da participação conceituando-a e destacando a necessidade que o ser humano tem de exercer o direito de participar das decisões diretamente relacionadas à sua própria existência e à vida em grupo. Dessa forma, objetivamos aprofundar os conhecimentos acerca da participação da comunidade no contexto organizacional. Fez-se uma análise dos dados coletados nas escolas públicas municipais na cidade de Salvador/Bahia com questões relativas à existência de mecanismos de acesso e suas dificuldades na participação da comunidade escolar na elaboração, acompanhamento e avaliação do PDE nas escolas municipais de Salvador. Tudo isso, no intuito de identificar o exercício da participação ativa e democrática da comunidade no processo da gestão participativa na escola.

\section{Participação}

O interesse da sociedade em fazer parte de um grupo, tomar parte das decisões e ter parte do resultado, tem se expandido nos últimos anos no Brasil e no mundo todo. Vê-se, nos dias atuais, a criação de um número cada vez maior de associações, movimentos organizados, grupos, comunidades, entre outros, buscando formas de participar das tomadas de decisões no seu ambiente. Segundo Motta (1997), a base cultural da política brasileira é as- 
sentada nos fundamentos da doutrina do "comando e do controle", o que dificulta sobremaneira a compreensão clara dos conceitos de participação que são definidos nas leis e explicitados nas suas regulamentações.

Um exemplo disso pode ser expresso nas diferentes compreensões que o termo "participação" adquire no dia-a-dia da gestão. Enquanto para alguns a participação significa apropriação do poder, para outros basta, para sua efetivação, a consulta aos envolvidos. Alguns empregam somente o termo participação, outros fazem referência à participação cidadã, societária, ou participação no desenvolvimento. Vejamos algumas dessas compreensões sobre o tema participação.

Para Modesto (1999), participar significa intervir num processo decisório qualquer e, no âmbito da administração pública, corresponde a todas as formas de interferência de terceiros na realização da função administrativa do Estado. De acordo com Diaz Bordenave (2002), a participação é um processo de desenvolvimento da consciência crítica e de aquisição de poder.

O Banco Interamericano para o Desenvolvimento (BID) (1991) define participação no desenvolvimento como o processo pelo qual as pessoas e entidades exercem influência no controle das iniciativas de desenvolvimento e nas decisões sobre recursos que os afetam.

Teixeira (2002) define a participação cidadã como um processo complexo e contraditório entre sociedade civil, Estado e mercado, em que os papéis se redefinem pelo fortalecimento dessa sociedade civil mediante a atuação organizada de indivíduos, grupos e associações.

Para Motta (1994, p. 9), a participação é uma forma de institucionalização do conflito capital-trabalho e de criação de mecanismos institucionais para a sua regulação, já que "o fator crucial para regular os conflitos efetivamente é o reconhecimento e, até mesmo, a ênfase na divergência sistemática e na oposição". Afirma, ainda, que a questão que se coloca para as sociedades modernas não é tanto a supressão do conflito, mas a possibilidade de sua antecipação e controle.

Segundo Demo (2001, p. 18), a participação é um processo dinâmico. Ele acredita também que a participação seja uma conquista social, um processo infindável de construção, que está sempre se fazendo. Ressalta que a "participação é em essência uma 
autopromoção e existe enquanto conquista processual. Não existe participação suficiente, nem acabada". Sendo assim, a participação que se imagina completa corre o risco de interromper o seu processo de construção.

Participação e comunidade se conjugam no caminho da interação social. De acordo com a ONU (NAÇÕES UNIDAS, 2001), participação é associar-se pelo pensamento, pelo sentimento e pela própria ação. Resulta daí não se entender participação simplesmente como forma de participação no mercado ou nos lucros. Participar é fazer saber, é comunicar, é comungar, é ter pontos em comum que nos levam à interação social, ou seja, aos processos sociais que nos dão condições para criar, manter e estimular as reações mútuas entre pessoas e grupos.

De acordo com Ortsman (1984), o mais importante da participação não é o quanto se toma parte, mas como se toma parte. Possivelmente, a insatisfação com a democracia representativa, que se nota nos últimos tempos em alguns países, inclusive no Brasil, deva-se ao fato de os cidadãos desejarem, cada vez mais, "tomar parte" no constante processo de tomada nacional de decisões e não somente nas eleições periódicas. A democracia participativa seria, então, aquela em que os cidadãos sentem que, por "fazerem parte" da nação, "têm parte" real na sua condução, e por isso, "tomam parte" - cada qual em seu ambiente - na construção de uma nova sociedade da qual se "sentem parte".

A interação social baseia-se na intercomunicação entre a comunidade e a organização. Tal interação metodiza-se em forma de diálogo. Participar é dialogar, é comungar interesses, sentimentos e ideias; é compartilhar experiências, é viver em comunidade e isso exige desprendimento do poder. Para Sievers (1994), a existência de uma verdadeira participação na administração só será possível se os segmentos reconhecerem a necessidade de abdicação, principalmente da parte dos administradores. A participação exige desprendimento do poder.

Há que se registrar, ainda, que a participação não é somente espontânea. Muitas vezes ela é e pode ser programada em qualquer tipo de organização ou instituição. Não obstante o fato de que participar é uma das grandes aspirações humanas, é lamentável que nem sempre essa vontade inata seja correspondida por aqueles que detêm o poder. (MOTTA, 1997) 


\section{Gestão participativa}

Examinado a literatura sobre a gestão participativa, pode-se perceber também, uma variada gama de definições, a exemplo de Matos (1979), que afirma ser a gestão participativa aquela em que, através de processos participativos, estimula a motivação, a cooperação e a liberação do potencial criativo da equipe, induzindo a um maior engajamento e corresponsabilidade por resultados.

Monlevade e Silva (2000) denominam gestão participativa a capacidade de os empregados influenciarem a tomada conjunta de decisões entre eles e os supervisores, especialmente quando ela afeta o trabalho dos empregados. Barros (1995) apresenta a gestão participativa como um direito igual para todos os associados em participarem da organização, através, principalmente, das assembleias gerais, partilhando igualmente dos benefícios e ônus resultantes de suas decisões.

Para Pinheiro, Méndez e O'Donnel (1994), a Constituição Federal do Brasil (CF), promulgada em 05 de outubro de 1988, traz algumas inovações em termos da democratização da escola. O Artigo 206 apresenta os princípios que devem servir de base para o ensino, dentre eles, o inciso VI diz: "Gestão democrática do ensino público, na forma da lei”. (BRASIL, 1998, p. 72)

A atual Constituição Estadual da Bahia, no que se refere à questão da Democratização da Gestão da Educação, foi mais detalhada que a Carta Magna definindo as funções do Conselho Estadual de Educação e criando os Colegiados Escolares:

Art. 249 - A gestão do ensino público será exercida de forma democrática, garantindo-se a representação de todos os segmentos envolvidos na ação educativa, na concepção, execução, controle e avaliação dos processos administrativos e pedagógicos.

$\S 10$ - A gestão democrática será assegurada através dos seguintes mecanismos:

I - Conselho Estadual de Educação;

II - Colegiados Escolares.

Embora houvesse um avanço na Constituição Estadual acerca da democratização na gestão escolar é, porém, na Lei Orgâni-

64 R. Faced, Salvador, n.13, p.59-82, jan./jun. 2008 
ca do Município de Salvador, promulgada em 1990, que a questão da democratização da educação ganha maior detalhamento. Embora já conquistada a eleição direta para diretor e vice-diretor desde 1986, no que diz respeito à questão da Democratização da Gestão da Educação, a Lei Orgânica do Município de Salvador foi ainda mais minuciosa.

\footnotetext{
Art. 186 - A Gestão do Ensino Público Municipal será exercida de forma democrática, garantindo a representação de todos os segmentos envolvidos na ação educativa, na concepção, execução, controle e avaliação dos processos administrativos e pedagógicos.
}

Parágrafo Único - A organização e funcionamento de Órgãos Colegiados, eleições diretas de diretores e vice-diretores de Unidades Escolares devem ser asseguradas, garantindo a gestão democrática e a autonomia da Unidade Escolar, a partir de eleições diretas para Diretores e Vices-Diretores. (SALVADOR, 2004)

Com a Lei Orgânica do Município de Salvador, em 1990, delineia-se o quadro institucional básico para a aplicação do processo de democratização da gestão da educação, iniciado com a Constituição Federal e, posteriormente, com a Constituição Estadual. A Lei Orgânica Municipal fecha um ciclo hierárquico institucional. Entretanto, entre o conteúdo da Lei e a sua efetivação, estabeleceram-se de fato grandes distâncias. Existem, todavia, algumas exceções, pois, graças, principalmente, a pressões exercidas pela sociedade organizada, é possível experimentar hoje novos paradigmas. (SANTOS, 2000) O país segue, dessa forma, sedimentando seu processo de democratização, tentando superar as sequelas da ditadura militar e os traços da mentalidade centralizadora e patrimonialista, tão largamente disseminados na sociedade brasileira.

As escolas municipais de Salvador pertencem a um contexto em que a participação da comunidade escolar em sua gestão é parte obrigatória de seu funcionamento. (SALVADOR, 2004) A gestão dessas escolas está associada a uma ação conjunta dos professores, alunos, funcionários e pais, que interagem, planejam e encaminham ações, objetivando atingir resultados coletivos construídos num clima democrático. O êxito desse tipo de gestão na escola estaria, nesse caso, ligado a uma vontade coletiva que orientaria as ações. 
De maneira abrangente, administração participativa é uma filosofia ou doutrina que valoriza a participação das pessoas no processo de tomada de decisões sobre os diversos aspectos das organizações. Essa definição tem diversas implicações, pois participar não é atitude natural nos modelos convencionais de administração, e muitos paradigmas subjacentes a esses modelos ajudam a manter a maioria dos trabalhadores alienados em relação ao controle de seu próprio trabalho e à gestão da organização. Essa alienação contribui para o desperdício do potencial de contribuição das pessoas. (BONAVIDES, 2001)

\section{Plano de Desenvolvimento da Escola (PDE)}

O Plano de Desenvolvimento da Escola (PDE) é um projeto resultante de um acordo de financiamento entre o Banco Mundial (BM) e o Ministério da Educação (MEC), desenvolvido em parceria com as secretarias estaduais e municipais de educação. A missão do programa é promover um conjunto de ações para a melhoria da qualidade das escolas do ensino fundamental, ampliando a permanência das crianças nas escolas públicas, nas regiões Norte, Nordeste e Centro-Oeste. Por força da vinculação a um financiamento do BM, conta com acompanhamento e avaliação do BM. Seu objetivo maior é reduzir as desigualdades escolares nos respectivos sistemas, aumentando a eficácia das escolas e levando as crianças dessas regiões a concluir com êxito o último ano do ciclo obrigatório do ensino fundamental.

Cada acordo de financiamento tem a duração de seis anos, em média. O "Acordo de Participação" inicial do PDE teve início em 1997. Para cumprir o objetivo previsto, o Programa propõe-se a desenvolver ações de fortalecimento da escola por meio de convênios com os municípios, mediante adesão dos mesmos. (AMARAL SOBRINHO; XAVIER, 1999) Estados, municípios e escolas devem adotar a metodologia de planejamento estratégico, consubstanciada no modelo do PDE, que leve à racionalização, eficácia e eficiência da gestão e do trabalho escolar.

Fala-se hoje com mais frequência de PDE. Isso é muito bom. Porém, esquece-se, muitas vezes, de mostrar a dimensão política do PDE. Fala-se em Plano de Desenvolvimento da Escola como se fosse uma coisa neutra, como se um plano como esse não estivesse situado num determinado contexto histórico-social e 
político. É também, um processo e um plano que implica diagnosticar uma situação e tomar decisões em função de um determinado fim. O PDE é um processo permanente que implica a avaliação constante de seu desenvolvimento com a participação de todos os segmentos da comunidade escolar em todo o seu processo. (AMARAL SOBRINHO; XAVIER, 1999)

Pode-se entender o PDE como um planejamento singular, próprio de cada instituição escolar. Para que ele seja eficaz, precisa ser coletivo. É coletivo quando inclui a participação de todos os envolvidos dentro de suas funções e atribuições. Esse Plano, por isso, precisa ser participativo. Mais do que uma atividade técnica é um processo político que deve incluir o maior número possível de membros da comunidade escolar. A decisão sobre o futuro da escola deve ser tomada pela maioria.

O acompanhamento do $\mathrm{PDE}$, no âmbito escolar, é realizado por uma equipe de sistematização e pelo Comitê Estratégico, que é composto pelo diretor da escola juntamente com o conselho escolar. A comunidade escolar deve participar de todas as etapas da constituição do PDE, desde a elaboração e proposição até a sua implementação, execução e avaliação. Essa diretriz garante um conteúdo democrático e educativo e contribui para que exista maior identidade entre as políticas públicas e a própria comunidade, requisito para que aquelas tenham eficácia e possam beneficiar esta última. (SANTOS, 2000)

O PDE aproxima a escola da racionalidade taylorista, na medida em que recupera princípios e métodos da gerência técnicocientífica: facilita a divisão pormenorizada do trabalho escolar, com nítida separação entre quem decide e quem executa as ações e fragmenta as ações escolares em inúmeros projetos desarticulados e com "gerências" próprias. De par com a fragmentação do trabalho, ocorre a diluição de poderes entre os membros da mesma coletividade, onde cada um é responsável apenas por uma parte do poder decisório. A concepção teórica já vem definida por "instâncias superiores". (AMARAL SOBRINHO; XAVIER, 1999)

Segundo Paro (1997), os gestores acreditam que estão dando uma direção ao trabalho escolar, por meio de uma metodologia quase infalível que, se seguida à risca, leva à participação coletiva em prol da melhoria da qualidade de ensino e do desempenho da escola. No entanto, essa racionalidade imposta à gestão não leva em conta o modo de ser e de agir que dão substância à cultura 
escolar, pois esta não é percebida como uma instituição complexa, cuja organização, gestão e produção do trabalho exigem iniciativas que ultrapassam os limites impostos pela racionalidade presente no modelo de planejamento estratégico.

Segundo Mello (1992), embora em sua concepção inicial o PDE enfatize a possibilidade de aumento do poder de decisão nas escolas, na prática, a própria sistemática de cofinanciamento internacional impõe instrumentos de controle sobre os projetos, como manuais para acompanhamento e planejamento de ações, além de normas para utilização de recursos e prestação de contas do dinheiro repassado à escola, para aquisição de materiais e melhoria do espaço escolar. Se, de um lado, esses instrumentos ajudam a organizar o trabalho rotineiro da escola, de outro, dificultam ou até mesmo impedem as decisões autônomas sobre outras questões mais gerenciais.

\section{Metodologia}

Os procedimentos metodológicos aplicados na pesquisa envolveram o levantamento bibliográfico das dimensões e variáveis relacionadas à participação da comunidade na gestão das organizações, a coleta e análise de dados em 11 escolas públicas municipais de Salvador. No intuito de encontrar possível resposta para o problema levantado, o método utilizado na pesquisa foi o estudo de caso, com a aplicação de um questionário composto por 34 questões (abertas e fechadas), das quais avaliaremos algumas poucas neste artigo.

A escolha dos entrevistados teve como elemento balizador a participação do sujeito no Conselho Escolar: como membro representante dos segmentos da comunidade escolar (pais, alunos, professores, funcionários e gestores) e com ocupação ou não de cargos (coordenador, vice-coordenador, secretário e tesoureiro) dentro do conselho.

Através de um sorteio, foram selecionadas 11 escolas de porte especial - escolas a partir de 501 alunos - para a composição da amostra. As escolas que compuseram a amostra foram convidadas, uma a uma, através de telefonemas, para que participassem dessa pesquisa A escolha dos membros do Conselho Escolar ficou a cargo do próprio Conselho e de acordo com a disponibilidade de cada um dos conselheiros para responder ao questionário.

68 R. Faced, Salvador, n.13, p.59-82, jan./jun. 2008 
Após contato telefônico, foram totalizados 55 conselheiros (cinco para cada segmento nas 11 escolas públicas municipais em Salvador) responsáveis em representar a comunidade escolar em cada um dos cinco segmentos que compõem o Conselho Escolar, conforme pode ser verificado na Tabela 1.

Tabela 1 - Quantidade de representantes do Conselho Escolar que responderam ao questionário.

\begin{tabular}{|c|c|c|c|c|c|c|}
\hline \multirow[t]{2}{*}{$\begin{array}{l}\text { Coordenadoria Regional } \\
\text { de Educação (CRE) }\end{array}$} & \multicolumn{5}{|c|}{ Números e representantes dos segmentos } & \multirow[t]{2}{*}{ TOTAL } \\
\hline & Alunos & Funcionários & Gestores & Pais & Professores & \\
\hline Cabula & 1 & 1 & 1 & 1 & 1 & 5 \\
\hline Cajazeira & 1 & 1 & 1 & 1 & 1 & 5 \\
\hline Centro & 1 & 1 & 1 & 1 & 1 & 5 \\
\hline Cidade baixa & 1 & 1 & 1 & 1 & 1 & 5 \\
\hline Itapuã & 1 & 1 & 1 & 1 & 1 & 5 \\
\hline Liberdade & 1 & 1 & 1 & 1 & 1 & 5 \\
\hline Orla & 1 & 1 & 1 & 1 & 1 & 5 \\
\hline Pirajá & 1 & 1 & 1 & 1 & 1 & 5 \\
\hline São Caetano & 1 & 1 & 1 & 1 & 1 & 5 \\
\hline Subúrbio I & 1 & 1 & 1 & 1 & 1 & 5 \\
\hline Subúrbio II & 1 & 1 & 1 & 1 & 1 & 5 \\
\hline Total de entrevistados & 11 & 11 & 11 & 11 & 11 & 55 \\
\hline
\end{tabular}

\section{Análise dos dados}

A seguir, serão apresentados e analisados os dados coletados através do questionário aplicado com os representantes dos segmentos pais, aluno, professor, funcionário e gestor no Conselho Escolar das escolas públicas municipais de Salvador. Esses dados foram coletados entre os dias 6 e 28 de março de 2006, com o objetivo de lançar luz sobre o problema deste trabalho.

\section{Acessibilidades da participação da comunidade escolar na elaboração, acompanhamento e avaliação do PDE nas escolas municipais de Salvador.}

Em se tratando de acesso à participação na gestão, a informação é um elemento de fundamental importância. Por meio do intercâmbio informacional, os sujeitos sociais se comunicam e tomam conhecimento de seus direitos e deveres, podendo dessa forma tomar decisões sobre suas vidas, individual ou coletivamente. As práticas de 
(2) Não corresponde ao valor acumulado e sim à totalidade de cada resposta. intercâmbio de informações podem ser conceituadas como ações de recepção, geração e transferência de informação que se desenvolvem e ajudam a formar as relações sociais. (CORDEIRO, 2001)

Considerando o que vimos no referencial teórico deste trabalho, percebe-se que o acesso à participação na elaboração, acompanhamento e avaliação do PDE passa pela construção e/ou práticas de cidadania dentro e fora da escola. Passa necessariamente, também, pelas questões do acesso e uso da informação, da organização em grupos, reuniões, da qualificação formal e informal do cidadão, da consulta e da delegação de poderes.

Para detectar se existiam mecanismos de acesso à participação da comunidade escolar na elaboração, acompanhamento e avaliação do PDE nas escolas municipais de Salvador, perguntamos aos representantes da comunidade escolar se havia acesso às informações financeiras, pedagógica e administrativa. Conforme os dados apresentados na Tabela 2, podemos verificar que 81,80\% do total ${ }^{2}$ dos entrevistados afirmaram que existe acesso às informações referentes ao PDE; 9,10\% afirmaram que "às vezes" existem informações e 9,10\% disseram que não existe o acesso às informações sobre o PDE. Podemos perceber que o segmento que mais recebeu informações sobre o PDE foi o gestor. E o segmento aluno, com 63,60\% foi o que menos recebeu informações sobre o PDE.

Daí que, segundo Motta (1997), a participação organizacional baseia-se na intercomunicação entre a comunidade e a organização. Para que haja uma participação mínima na gestão da escola, é necessário que se disponha de informações. A falta de informações ajuda a manter alienados os trabalhadores, no que diz respeito aos seus direitos, e dificulta o controle sobre as decisões na organização. (BONAVIDES, 2001)

Tabela 2 - Existência de acesso às informações sobre o PDE

\begin{tabular}{|c|c|c|c|c|c|}
\hline & & \multicolumn{3}{|c|}{$\begin{array}{l}\text { Você recebeu informações importantes sobre } \\
\text { as matérias envolvidas com o PDE? }\end{array}$} & \multirow[t]{2}{*}{ Total } \\
\hline & & Sim & Não & Às vezes & \\
\hline \multirow[t]{5}{*}{ Segmento } & Aluno & $63.60 \%$ & $18.20 \%$ & $18.20 \%$ & $100.00 \%$ \\
\hline & Pais & $90.90 \%$ & $0,00 \%$ & $9.10 \%$ & $100.00 \%$ \\
\hline & Professor & $81.80 \%$ & $0,00 \%$ & $18.20 \%$ & $100.00 \%$ \\
\hline & Funcionário & $72.70 \%$ & $27.30 \%$ & $0,00 \%$ & $100.00 \%$ \\
\hline & Gestor & $100.00 \%$ & $0,00 \%$ & $0,00 \%$ & $100.00 \%$ \\
\hline Total & & $81.80 \%$ & $9.10 \%$ & $9.10 \%$ & $100.00 \%$ \\
\hline
\end{tabular}

FONTE: Questionários aplicados, 2006

70 R. Faced, Salvador, n.13, p.59-82, jan./jun. 2008 
Segundo Oliveira (2002), a participação pode ser maior ou menor dependendo do grau e da fluidez com que as informações circulam nas empresas. Se a participação está diretamente associada à informação, podemos dizer, com base nos dados, que o segmento aluno tem uma participação menor que os demais segmentos; enquanto a maior participação no processo é concedida ao segmento gestor.

Esses dados confirmam a opinião de Brandão (1998), quando diz que determinados grupos ainda concentram informações importantes na gestão organizacional, sendo possível perceber, através dos dados, que os segmentos professor e gestor têm acesso a documentos que, em geral, os demais segmentos não têm.

Além de investigarmos a acessibilidade da comunidade escolar na busca de informações sobre o PDE, procuramos saber que meios os gestores utilizavam para passar as informações acerca das ações aos outros segmentos do Conselho Escolar. Os dados da Tabela 3 nos mostram que $80 \%$ do segmento gestor utilizam as reuniões como estratégia de comunicação para passar à comunidade as informações concernentes ao PDE, 17\% usam os avisos escritos para se comunicar, e 3\% não utilizam nenhuma estratégia de diálogo com a comunidade.

Pelos dados da Tabela 3, percebemos que os gestores utilizam-se das reuniões como principal meio de comunicação entre a diretoria e a comunidade, para passar informações sobre o PDE. Esses dados corroboram com as informações de Paro (1997), que afirma que o gerente tende a lançar mão das reuniões como um instrumento fundamental para a implementação de uma gestão participativa. As reuniões, segundo o autor, devem ter como objetivo sensibilizar seus colaboradores, contribuir para a união do grupo, delegar tarefas, desenvolver a iniciativa e a criatividade.

Tabela 3 - Meios utilizados pelo gestor para informar a comunidade sobre o PDE

\begin{tabular}{lllll}
\hline & Reuniões & Avisos escritos & Nenhuma & Total \\
Gestor & $80,00 \%$ & $17,00 \%$ & $3,00 \%$ & $100,00 \%$ \\
\hline
\end{tabular}

FONTE: Questionários aplicados, 2006

As reuniões são os principais instrumentos de acesso à gestão da escola e de interação entre a comunidade e a direção da escola; dessa forma, procuramos averiguar com que frequência elas eram realizadas anualmente. Os dados da Tabela 4 nos infor- 
mam que $45,50 \%$ do total dos segmentos disseram que as reuniões com a comunidade ocorrem de 3 a 4 vezes por ano, enquanto $25,50 \%$ afirmaram que as reuniões acontecem de 5 a 6 vezes por ano. Se acumularmos esses dois percentuais, teremos $71 \%$ de reuniões, numa média de 4 a 5 reuniões anuais. Um número bastante ínfimo se levarmos em consideração a legislação que regulamenta os conselhos escolares, que determina uma reunião ordinária mensal. ${ }^{3}$ Isso mostra ser necessário haver mais reuniões, no intuito de aumentar as informações e crescer o compromisso e a participação da comunidade.

Tabela 4 - Frequência das reuniões anualmente

\begin{tabular}{|c|c|c|c|c|c|c|c|}
\hline & & \multicolumn{5}{|c|}{$\begin{array}{l}\text { Com que frequência a comunidade escolar } \\
\text { se reúne anualmente? }\end{array}$} & \multirow[t]{2}{*}{ Total } \\
\hline & & Até $2 \mathrm{x}$ & 3 a $4 x$ & 5 a $6 x$ & 7 a $8 x$ & Mais de $9 x$ & \\
\hline \multirow[t]{5}{*}{ Segmento } & Alunos & $36,40 \%$ & $27,30 \%$ & $27,30 \%$ & $0,00 \%$ & $9,10 \%$ & $100,00 \%$ \\
\hline & Pais & $18,20 \%$ & $45,50 \%$ & $27,30 \%$ & $0,00 \%$ & $9,10 \%$ & $100,00 \%$ \\
\hline & Professor & $9,10 \%$ & $45,50 \%$ & $27,30 \%$ & $9,10 \%$ & $9,10 \%$ & $100,00 \%$ \\
\hline & Funcionário & $0,00 \%$ & $54,50 \%$ & $18,20 \%$ & $27,30 \%$ & $0,00 \%$ & $100,00 \%$ \\
\hline & Gestor & $0,00 \%$ & $54,50 \%$ & $27,30 \%$ & $18,20 \%$ & $0,00 \%$ & $100,00 \%$ \\
\hline Total & & $12,70 \%$ & $45,50 \%$ & $25,50 \%$ & $10,90 \%$ & $5,50 \%$ & $100,00 \%$ \\
\hline
\end{tabular}

FONTE: Questionários aplicados, 2006

Esses dados confirmam, portanto, a opinião de Cordeiro (2001), quando diz que a informação é um componente importante para o acesso à participação da comunidade. Nesse sentido, encontramos nas escolas públicas municipais de Salvador a existência de alguns mecanismos de acesso, para participação da comunidade, às informações acerca do PDE, a exemplo de reuniões do próprio Conselho as legislações pertinentes, eleições de diretores. No entanto, para que haja uma participação efetiva, faz-se necessário que esses mecanismos de informações sejam executados com eficiência e no mais alto nível de transparência. (PARO, 1997) Porque nem todos os assuntos da escola são de atribuição do Conselho de Escola. Pois aquele espaço, com respaldo na legislação, que se constitui em prerrogativas da direção, sobre as quais não cabem interferências. E isso deve estar claro para os participantes.

Os dados analisados até aqui nos informam que existe uma quantidade grande de informações nas mãos do segmento gestor. Sabendo disso, os outros segmentos buscam a direção da escola 
para receber as informações. Vimos que também existe uma transferência de informações para os diversos segmentos, por iniciativa do gestor, por meio de reuniões e avisos escritos, em tempo hábil. No entanto, desconhecemos em que quantidade e qualidade as informações são passadas para esses segmentos.

Pudemos perceber que, de acordo com os dados desta questão de pesquisa, as principais ações adotadas pelos gerentes das escolas públicas do município de Salvador são as reuniões e os projetos. Isso coincide com o nosso referencial, que preconiza as reuniões como o principal meio de comunicação entre a direção e a comunidade escolar. (PARO, 1997) Segundo Amaral Sobrinho e Xavier (1999), o diretor deve promover reuniões frequentes da comunidade escolar - pais alunos professores e funcionários - a fim de que se possa envolvê-la na construção de um projeto de participação.

Vimos que os projetos são também bastante utilizados pelos gestores como instrumentos de incentivo à participação no PDE. A direção da escola, através dos eventos proporcionados pelos projetos, procura envolver a comunidade nas decisões relativas ao PDE, enfatizando a sua participação e promovendo, em consequência, um alargamento da consciência e da competência técnica.

Dificuldades na participação da comunidade escolar na elaboração, acompanhamento e avaliação do PDE nas escolas municipais de Salvador

Apesar de todos os segmentos terem participado do processo que envolve o PDE, a Tabela 5 nos mostra que somente os segmentos gestor e professor coordenaram-lhe as atividades, cabendo $70 \%$ dessa coordenação ao primeiro e 30\% ao segundo. Mais uma vez percebemos um controle de poder da parte desses dois segmentos. Isso reforça a ideia de controle do poder exercido pelo gestor e pelo professor dentro do PDE, já que 100\% dos PDE ficaram sob a coordenação dos segmentos gestor e professor, enquanto os demais segmentos foram alijados do controle formal do Conselho Escolar.

Para Sievers (1994), a existência de uma verdadeira participação na administração só será possível se os segmentos reconhecerem a necessidade de abdicação, principalmente da parte dos administradores. A participação exige desprendimento do poder.

R. Faced, Salvador, n.13, p.59-82, jan./jun. $2008 \mathbf{7 3}$ 
Tabela 5 - Os Coordenadores do processo

\begin{tabular}{ll}
\hline Segmentos & Coordenadores do processo do PDE \\
\hline Aluno & $0,00 \%$ \\
Pais & $0,00 \%$ \\
Professor & $30,00 \%$ \\
Funcionário & $0,00 \%$ \\
Gestor & $70,00 \%$ \\
\hline Total & $\mathbf{1 0 0 , 0 0 \%}$
\end{tabular}

FONTE: Questionários aplicados, 2006

Segundo Abranches (2003), as reuniões do Conselho precisam ter uma linguagem simples, objetiva e com vistas ao entendimento de todos. A Tabela 6 nos informa que nem todos os segmentos têm uma boa compreensão do que está sendo discutido nas reuniões. Isso é importante, pois se não houver uma linguagem acessível a todos os segmentos a compreensão ficará comprometida, e, por extensão, também a participação. Em conformidade com os dados, um total de $65,45 \%$ disse que o nível de linguagem utilizado nas reuniões é de fácil compreensão.

Em âmbito geral, os dados indicaram o processamento de uma boa compreensão nas reuniões, já que a maioria dos membros do Conselho Escolar afirmou entender o que é discutido nelas. No entanto, ainda existem algumas pessoas que não compreendem o que é discutido nas reuniões. Essas pessoas estão localizadas, sobretudo, nos segmentos alunos e pais, onde contam $72,70 \%$ para cada segmento. Isto indica que estes dois segmentos enfrentam uma maior dificuldade em compreender as informações nas reuniões.

Tabela 6 - Nível de compreensão da linguagem nas reuniões

\begin{tabular}{|c|c|c|c|c|c|}
\hline & & \multicolumn{3}{|c|}{$\begin{array}{l}\text { O nível de linguagem utilizado nas reuniões } \\
\text { permite a compreensão do que está sendo discutido? }\end{array}$} & \multirow[t]{2}{*}{ Total } \\
\hline & & Sim & Não & Ás vezes & \\
\hline \multirow[t]{5}{*}{ Segmentos } & Alunos & $27,30 \%$ & $72,70 \%$ & 0,00 & $100,00 \%$ \\
\hline & Pais & $18,20 \%$ & $72,70 \%$ & $9,10 \%$ & $100,00 \%$ \\
\hline & Professor & $90,90 \%$ & 0,00 & $9,10 \%$ & $100,00 \%$ \\
\hline & Funcionário & $90,90 \%$ & 0,00 & $9,10 \%$ & $100,00 \%$ \\
\hline & Gestor & $100,00 \%$ & 0,00 & 0,00 & $100,00 \%$ \\
\hline Total $^{4}$ & & $65,45 \%$ & $29,10 \%$ & $5,45 \%$ & $100,00 \%$ \\
\hline
\end{tabular}

Essa ocorrência numérica reflete-se nas decisões tomadas pelo Conselho Escolar. Como podemos verificar, apesar de todos os

74 R. Faced, Salvador, n.13, p.59-82, jan./jun. 2008 
membros participarem formalmente do processo decisório, a Tabela 7 nos mostra que os segmentos professor e gestor têm uma parcela maior de contemplação nas propostas. O caso mais grave é do segmento aluno, que não tem proposta contemplada no PDE. O segmento gestor tem $81,80 \%$ das propostas constantes do PDE, seguido do segmento professor com 63\% das propostas. O segmento funcionário, com apenas 9,09\% das propostas contempladas, tem uma contemplação menor que a do segmento pais.

Isso indica que apesar do segmento gestor respeitar as decisões tomadas dentro dos conselhos, ele ainda é o principal concentrador do poder das informações e dos cargos de coordenação dos processos do PDE. Usando uma linguagem que nem todos os segmentos conseguem compreender, o gestor consegue dirigir os processos de decisão, de modo que, ao final dos processos, o PDE, que deveria ser um instrumento de construção coletiva e de acesso à participação, acaba não refletindo na prática essa coletividade e acessibilidade.

Tabela 7 - Propostas contempladas no PDE

\begin{tabular}{|c|c|c|c|c|}
\hline \multirow[t]{2}{*}{ Segmentos } & \multicolumn{3}{|c|}{ No PDE está contemplada alguma proposta sugerida por você? } & \multirow[t]{2}{*}{ Total } \\
\hline & Sim & Não & Outros & \\
\hline Aluno & $0,00 \%$ & $90,90 \%$ & $9,10 \%$ & $100,00 \%$ \\
\hline Pais & $36,40 \%$ & $63,60 \%$ & $0,00 \%$ & $100,00 \%$ \\
\hline Professor & $63,60 \%$ & $36,40 \%$ & $0,00 \%$ & $100,00 \%$ \\
\hline Funcionário & $9,10 \%$ & $81,80 \%$ & $9,10 \%$ & $100,00 \%$ \\
\hline Gestor & $81,80 \%$ & $18,20 \%$ & $0,00 \%$ & $100,00 \%$ \\
\hline Total $^{5}$ & $38,20 \%$ & $58,20 \%$ & $3,60 \%$ & $100,00 \%$ \\
\hline
\end{tabular}

FONTE: Questionários aplicados, 2006

(5) Não corresponde ao valor acumulado, mas sim à totalidade de cada resposta.

Essa situação de centralização do poder não contribui para uma participação democrática no seio da gestão escolar, pois, segundo Sievers (1994), a participação efetiva na administração deve estar acompanhada da delegação de poderes, para que administradores e outros segmentos possam conjuntamente construir uma relação democrática.

Outros dados indicam a centralização do poder. Observemos a Tabela 8, que nos mostra claramente que mais de $90 \%$ do segmento gestor que está no Conselho Escolar ocupa-lhe o cargo de coordenador. Em seguida, 27,30\% dos professores que estão no Conselho exercem o cargo de coordenador, enquanto $54,50 \%$ desse segmento preenchem o cargo de vice-coordenador. É válido 
(6) Diário Oficial do Município de Salvador - Estado da Bahia, 2005

salientar que os cargos do Conselho são distribuídos entre os próprios membros, na primeira reunião depois de eleitos. Cabe ainda salientar que o coordenador é o que convoca e preside as reuniões, representa o Conselho, assina cheques, etc ${ }^{6}$.

Tabela 8 - Ocupação dos cargos no Conselho escolar

\begin{tabular}{|c|c|c|c|c|c|c|c|}
\hline \multicolumn{7}{|c|}{ Cargos do Conselho Escolar } & \multirow[t]{2}{*}{ Total } \\
\hline & & Coordenador & Vice-coordenador & Secretária & Tesoureiro & Membro & \\
\hline \multirow[t]{5}{*}{ Segmentos } & Aluno & $0,00 \%$ & $0,00 \%$ & $0,00 \%$ & $0,00 \%$ & $100,00 \%$ & $100,00 \%$ \\
\hline & Pais & $9,10 \%$ & $0,00 \%$ & $0,00 \%$ & $0,00 \%$ & $90,90 \%$ & $100,00 \%$ \\
\hline & Professor & $27,30 \%$ & $54,50 \%$ & $0,00 \%$ & $9.10 \%$ & $9.10 \%$ & $100,00 \%$ \\
\hline & Funcionário & $0,00 \%$ & $0,00 \%$ & $81,80 \%$ & $9,10 \%$ & $9,10 \%$ & $100,00 \%$ \\
\hline & Gestor & $90,90 \%$ & $9,10 \%$ & $0,00 \%$ & $0,00 \%$ & $0,00 \%$ & $100,00 \%$ \\
\hline Total & & $25,50 \%$ & $12,70 \%$ & $16,40 \%$ & $3,60 \%$ & $41,80 \%$ & $100,00 \%$ \\
\hline
\end{tabular}

FONTE: Questionários aplicados, 2006

E onde estão os outros segmentos? 100\% do segmento aluno, na mesma Tabela 8, aparecem meramente como membros do Conselho, ou seja, não exercem cargos dentro do Conselho; 90,90\% do segmento pais também estão sem cargo no Conselho; 81,80\% do segmento funcionário está como secretário do Conselho Escolar, provavelmente porque os representantes desse segmento já fazem parte da secretaria da escola. Quiçá, tudo isso seja mais uma causa da concentração das decisões no Conselho Escolar nas reuniões decisórias do PDE nas mãos dos gestores

Os segmentos pais e alunos têm uma grande dificuldade de serem eleitos para ocupar os cargos dentro do Conselho Escolar. Os dados dessa pesquisa indicam que apesar dos segmentos aluno, pais e funcionário participarem maciçamente de todo o processo de elaboração, acompanhamento e avaliação do PDE por meio das reuniões, os gestores coordenam todo o processo e terminam por decidi-los e, sendo assim, esse último segmento é o principal protagonista do processo.

Ao verificarmos as Tabelas 7 e 8, notamos que quem decide, quem toma as decisões dentro do Conselho são, majoritariamente, os gestores e os professores. Eles são os principais idealizadores das propostas contidas no PDE. Isso confirma ainda mais a ideia de que apesar dos esforços de descentralizar as decisões e apesar das legislações favoráveis a esse respeito, ainda existe uma con-

76 R. Faced, Salvador, n.13, p.59-82, jan./jun. 2008 
centração de poder do processo decisório nas mãos dos segmentos gestor e professor, o que dificulta a participação de outros segmentos na gestão escolar.

Durante as reuniões do Conselho para a tomada de decisão, todos os segmentos participam, todos os segmentos estão representados, mas nem todos participam democraticamente do processo. Parcelas de alguns segmentos têm dificuldades de entender e de se expressar nas reuniões. O que é decidido é respeitado, mas, no final das contas, as propostas do PDE estão relacionadas aos segmentos professor e gestor, indicando que as decisões do Conselho estão sempre concentradas nesses segmentos.

Isso confirma o aspecto paradoxal da participação. Segundo Ortsmanm (1984), é possível o indivíduo fazer parte sem tomar parte. Os resultados analisados até aqui têm demonstrado que determinados segmentos fazem parte sem porém tomar parte do processo. Isso equivale ao que o autor chama de participação passiva. A comunidade escolar participa do Conselho, inclusive por força de legislação, vai às reuniões para a tomada de decisões e, ao chegar lá, não tem sido concedida a força suficiente para decidir. Dessa maneira, ficam a maioria das decisões a cargo dos segmentos professor e gestor, este último também um professor. Essa situação dificulta a participação de alguns segmentos da comunidade na gestão escolar, sobretudo, pais e alunos.

Segundo os dados, em geral, os segmentos recebem informações acerca do PDE. E esses subsídios vêm dos gestores, porque é nesse segmento que estão concentradas as informações sobre o PDE. O apoio da liderança do gestor nas relações humanas, as convocações de reuniões, os projetos inclusivos podem ajudar para a existência de um clima favorável à participação. Esses incentivos, de acordo com Brito (2004), são mecanismos que favorecem o acesso da comunidade aos circuitos de decisão central, e devem ser encorajados pelas organizações e seus representantes.

\section{Conclusões}

A descentralização da gestão da escola pública não está voltada apenas à autonomia administrativa, pedagógica e financeira das escolas, mas trata-se, principalmente, da atuação do professor, do aluno, do funcionário e dos pais, visando facilitar o acesso à gestão da escola e superar as fraquezas institucionais e huma- 
nas que geram fatores que dificultam o processo de formação da gestão participativa. Ao aprofundar os conceitos acerca da participação da comunidade no contexto organizacional, discutindo sobre os mecanismos de acesso à participação da comunidade escolar na gestão da escola e as suas dificuldades, acredita-se ter atingido o objetivo dessa pesquisa, visto que identificou-se instrumentos de acesso à participação ativa para segmentos hegemônicos que dominam o processo controlando as tomadas de decisão. Entretanto, para os segmentos pais e alunos, as dificuldades são numerosas.

Feitas as análises dos dados e após essas considerações, é possível refletir sobre o problema: Quais os acessos e dificuldades da participação da comunidade na gestão das escolas públicas municipais de Salvador? Temos, então, a seguinte resposta: a exemplo das diversas leis que criam mecanismos de participação, conselhos escolares, eleições de diretores, programas de incentivos à participação da comunidade escolar por parte da SMEC e da escola, descentralização através das CRE, reuniões com a participação de todos os segmentos da comunidade escolar, apesar da presença desses mecanismos, as equipes gestoras das escolas não têm conseguido tratar deles, eficazmente, permitindo o acesso a uma participação igualitária a todos os segmentos que compõem a comunidade escolar.

Dessa forma, os poder ainda está centralizado nas mãos dos gestores e de professores que não conseguem perceber a inexistência de uma participação democrática na gestão das escolas. Ocorre que outros segmentos, como pais, alunos e funcionários, apesar de fazerem parte da comunidade escolar, não têm tomado parte nas decisões, pois os mecanismos de participação não funcionam para eles. Não basta os gestores fazerem reuniões com todos os representantes da comunidade e apenas uma parte desses representantes decidir, restando à outra dar o aval para referendar as decisões.

Percebemos que, apesar de toda a comunidade escolar estar formalmente representada no Conselho Escolar, uma quantidade expressiva dela não participou das tomadas de decisões, não teve propostas contempladas e não se reconhece, ao final do processo, no PDE. Isso denuncia a centralização do poder nas mãos dos gestores e a falta de diálogo suficiente durante as reuniões do 
conselho. A lacuna existente entre a gestão e a comunidade escolar pode ter sido provocada pelo desconhecimento dos gestores de que todos os segmentos deveriam participar do processo do PDE, ou pelo fato de que os diversos segmentos não estavam munidos de informações suficientes para atuarem de forma mais presente no processo, ou ainda pela falta de interesse ou tempo disponíveis de parte dos conselheiros para integrar-se à equipe.

De fato, os dados mostraram que as decisões acerca do PDE são tomadas por um conselho, cujas atividades principais são coordenadas pelos gestores ou pelos professores. Possivelmente, essas práticas de centralização são frutos de nossa inexperiência democrática, os quais se convertem em antiparticipação, antidemocratização e antirresponsabilidade, visto que carecemos, em nossa formação histórico-cultural, de experiências democráticas. Essa situação deve ser superada com o desejo de confiar, cooperar e delegar poderes, da parte dos diversos segmentos sociais, uns em relação aos outros.

Resguardadas as devidas proporções, o PDE tem se constituído em um instrumento de abertura de espaço à participação da comunidade na gestão da escola. Além de existirem outros instrumentos de acesso à gestão já citados nesse trabalho. Parecem relevantes os esforços que os gestores têm feito para consolidar a participação da comunidade na gestão escolar, mas pensamos ser um equívoco considerar a participação um ato de convocar pessoas, colocá-las sentadas numa sala e comunicar o que elas devem fazer. Ou ainda, apenas chamar as pessoas e perguntar o que elas precisam ou o que elas acham disso ou daquilo e depois não fazer nada com o que foi dito, ou fazer apenas ações assistencialistas.

Porém, para que a participação se efetue de uma maneira efetiva e real, faz-se necessária a utilização destas ferramentas de um jeito mais eficaz, pois os segmentos pais, alunos e funcionários, os mais excluídos, precisam sentir-se partes integrantes desse processo que move a organização escolar. Eles não devem sentirse como massa de manobra, ou ter a sensação de que estão presentes apenas para o cumprimento protocolar de legislações. O acesso à gestão nas escolas públicas municipais de Salvador já está garantido, a democratização do espaço dentro do CE ainda é uma das dificuldades a ser superadas na gestão participativa. 
The administration participativa at savior municipal public schools and the involvement school community level

ABSTRACT: This article introduces the result of a research accomplished in 2006, involving the thematic participation. It boards the accesses and the difficulties in the community's school participation (parents, students, teachers, employees and managers) in the municipal public schools administration in Salvador. In the problem formulation was going defined the following matter: which ones the community participation accesses and difficulties in the administration Salvador's municipal public schools? The research objective mains were: deepen the knowledges concerning the community's participation in the context organizacional and to evaluate the participation school community amplitude in the school administration through the elaboration, School Development Plan accompaniment and evaluation (PDE) at municipal schools of Salvador. The used methodology was the study of case. The result of investigation introduced objective and subjective forms that facilitate and complicate community's school effective participation by means of the School Board (CE) in an perspective emancipável administration. And it points a decisive power concentration in the segments managers and teachers hands. This last in smaller degree.

KEYWORDS: Democratic Administration at School. Democratic participation.

\section{Referências}

ABRANCHES, Mônica. Colegiado escolar: espaço de participação da comunidade. São Paulo: Cortez, 2003.

AMARAL SOBRINHO, J; XAVIER, Antônio C. R. Como elaborar o Plano de Desenvolvimento da Escola - PDE. Brasília: MEC/FUNDESCOLA, 1999.

ARNSTEIN, Sherry R. A ladder of citizen participation. Journal of American Institute Planners, v. 35, n. 3, p. 216-224, 1969.

BANCO INTERAMERICANO PARA O DESENVOLVIMENTO (BID). Libro de consultas sobre participación. [S.1., 199-]. Disponível em: <www.iadb.org.org.exr/ESPANHOL/politicas/participa/indice.htm >. Acesso em: 15 set. 2003.

BAHIA. [Constituição]. Constituição do Estado da Bahia. 2. ed. Salvador: EGBA, 1990.

BARROS, Claudius D'Artagnan C. de. Qualidade e participação: o caminho para o êxito. 3. ed. São Paulo: Nobel, 1995.

BONAVIDES, Paulo. Teoria constitucional da democracia participativa: por um direito constitucional de luta e resistência, por uma nova hermenêutica, por uma repolitização da legitimidade. São Paulo: Malheiros, 2001.

BRANDÃO, Maria de Azevedo. Origens da expansão periférica de Salvador. Planejamento. Salvador, v.6, n.2, p.155-172, abr./jun., 1998.

80 R. Faced, Salvador, n.13, p.59-82, jan./jun. 2008 
BRASIL. [Constituição]. Constituição da República Federativa do Brasil. 18. ed. atualizada e ampliada. São Paulo: Saraiva, 1998.

BRASIL. Lei n. 9.394, de 20 dezembro de 1996. Estabelece as diretrizes e bases da educação nacional. Disponível em: < http:// portal.mec.gov.br/seed/arquivos/pdf/tvescola/leis/lein9394.pdf > . Acesso em: 2 de mar. 2007.

BRITO, Marcelo Sousa; SERPA, Angelo. Percepção e cultura na periferia de Salvador: o bairro em imagens, uma experiência de ensino, extensão e pesquisa. In: CONGRESSO BRASILEIRO DE EXTENSÃO UNIVERSITÁRIA, 2., 2004, Belo Horizonte. Anais... Belo Horizonte: UFMG, 2004.

CORDEIRO, Márcia de Freitas. Bairro e identidade cultural na periferia de Salvador. Salvador: PIBIC/CNPq, UFBA, 2001. Relatório final de pesquisa. p. 234-234.

DEMO, Pedro. Participação é conquista: noções de política social. 5. ed. São Paulo: Cortez, 2001.

DIAZ BORDENAVE, Juan E. O que é participação. 8. ed. São Paulo: Brasiliense, 2002.

MATOS, Francisco Gomes. Gerência participativa: como obter a cooperação espontânea da equipe e desburocratizar a empresa. São Paulo: LTC, 1979.

MELLO, Guiomar Namo de; SILVA, Rose N. Política educacional no Governo Collor: antecedentes e contradições. Brasília: Iesp/ Fundap, 1992. (Texto para Discussão, n. 3).

MODESTO, Paulo. Participação popular na administração pública: mecanismos de operacionalização. JusVigilantibus, Vitória, 1999. Disponível em: < www.apoena.adv. br/participacao-popular-naadminist >. Acesso em: 05 ago. 2005.

MONLEVADE, J.; SILVA, M.A. Quem manda na educação no Brasil. Brasília, DF: Idea, 2000.

MOTTA, Fernando C. Prestes. Cultura e organizações no Brasil. In: (Org.). Cultura organizacional e cultura brasileira. São Paulo: Atlas, 1997.

Participação e co-gestão: novas formas de administração. 2. ed. São Paulo: Brasiliense, 1994.

NAÇÕES UNIDAS. Relatório contra a Tortura. Organização das Nações - ONU. Documento CAT/C/XXVI/Concl.6/Rev.1. Genebra, 2001.

OLIVEIRA, R. P.; SILVA, G. P. Planejamento Estratégico no Pró-Criança. Trabalho apresentado no V Encontro de Extensão da UFPE, 2002.

ORTSMAN, O. Mudar o trabalho: as experiências, os métodos, as condições de experimentação social. Lisboa: Fundação Calouste Gulbenkian, 1984. 
PARO, Vitor Henrique. Gestão democrática da escola pública. São Pau1o: Ática, 1997.

PINHEIRO, P. S.; MÉNDEZ, J. E.; O’DONNEL, G. Democracia, exclusão e injustiça: o não-estado de direito na América Latina. São Paulo: Paz e Terra, 1994.

PINTO, João Bosco. G. Planejamento participativo na escola cidadã. In: SILVA, Luiz Heron da; AZEVEDO, José Carlos de (Org.). Paixão de aprender II. Petrópolis: Vozes, 1995.

SALVADOR. Lei Complementar n. 036, de 30 de abril de 2004. Dispõe sobre o Estatuto dos Servidores do Magistério Público do Município de Salvador. Salvador: Câmara Municipal, 2004.

Lei Orgânica do Município do Salvador. Salvador: Câmara Municipal, 1990.

SANTOS, Milton. Por uma outra globalização: do pensamento único à consciência universal. Rio de Janeiro: Record, 2000.

SIEVERS, Burkard. Work, death, and life itself: essays on management and organization. Berlin; New York: Walter de Gruyter, 1994.

TEIXEIRA, Lucia Helena Gonçalves. Cultura organizacional e projeto de mudança em escolas pública. Campinas, SP: Autores Associados, 2002. 